\title{
A Survey: Slot Antenna and Antenna Array.
}

\author{
Sudarshan Bhat ${ }^{1}$ and Priyadarshini K Desai ${ }^{2}$ \\ ${ }^{1}$ BNM Institute of Technology,Bangalore, karnataka \\ ${ }^{2}$ BNM Institute of Technology,Bangalore, Karnataka \\ ${ }^{1}$ uniquesud@gmail.com, ${ }^{2}$ priyadarshini.p.r@gmail.com
}

\begin{abstract}
Slot are generally introduced in the antenna or antenna to improve the impedance matching, improve the bandwidth and gain. Sometimes slots are introduced in the ground planes, or between antenna elements to reduce the mutual coupling between elements. The antenna being an important element in a wireless communication technology, the design of the same with different requirements is important. This paper gives the survey of the slot antenna and antenna array constructed through waveguide and microstrip lines, to meet different antenna parameters as required in various wireless communication technology.
\end{abstract}

Keywords: slot antenna,slot antenna array, gain bandwidth, polarization.

\section{Introduction}

Slotare produced by making a lengthened or prolonged slot cut of about $0.5 \lambda$ long and width usually very less than $0.5 \lambda$ in a conductive metal sheet and is often excited at the center or off the center. Shape of slot is usually available in the form circular or rectangular and these are in the form of width modification, due to which it is capable of being acted as a waveguide, coplanar waveguide (CPW), coaxial, slot line, or as a microstrip feeding schemes. Slot creation leads to obtaining a new resonating frequency Creating or introducing a slot in the bottom layers, of the microstrip antennasoffersincreases in antenna gain. The radiation pattern of the slot antennas is most of the omni directional, featuring omni directional gain around the azimuth plane with horizontal polarization.

Slots creation the waveguide antenna, termed slotted waveguide antenna, is basically an array of slots, offers a very high gain and are capable of operating in the frequency range $300 \mathrm{MHz}$ to $30 \mathrm{GHz}$. For the lower microwave frequency as well as ultra-highfrequency, a slotted-cylinder antennais used.

Slot introduction has an added advantage of getting different polarization, as a simple example, the complement of a dipole when placed in free space is a thin slot in an infinite ground plane, consider slot and dipole have same dimension, then the corresponding radiation will be same except that $\mathrm{E}$ - and $\mathrm{H}$ - fields are swapped, that is slot acts as magnetic dipole rather than an electric dipole. As a result, the polarization is rotated $90^{\circ}$, so that radiation from a vertical slot is polarized horizontally while aifvertical slot is introduced antenna gives the horizontally polarized signal.

Thus, slot cutting or introduction forming slot antenna and slot antenna seems to have many advantages with respect to getting desired antenna parameters such as 
increase in gain, efficiency, required polarization and bandwidth. This paper gives the survey of the slot antenna and slot antenna array used in various scenarios to meet the required criteria with respect to the different application.

\subsection{Slot introduction in antenna and antenna array to meet desired result.}

A Dual feature, male tapered slotoperated as an antenna predefined at a frequency of $28 \mathrm{GHz}$ was basically used to excite dipole antenna resonating at $3.6 \mathrm{GHz}$ as mentioned in [7]. Slot with C shape with 50-ohm microstrip fed discussed in [15] offered left-hand polarization. In [14], bow-tie slot antenna was used to get a wide impedance bandwidth, with the threelayer groove structure to provide strong mechanical support and enhanced gain. The square ring slot radiator in [13] was designed to provide dual-polarization characteristics maintaining the performances better in terms of fundamental radiation characteristics. Design of cubic slot in [12] could switch between omni-directional and broadside radiation pattern. A compact large-declination longitudinal slot array antenna developed in [11] achieves a larger off angle[declination] and a lower side lobe level.

Circularly polarized, backed slot spiral antenna array designed in [09] and fed by PGW provides higher efficiency.Radial line slot array with Circularly polarized (CP RLSA) [8] antenna with a gradually variation of length of slot along with radius, for reducing the antenna side-lobe levels and for making uniform aperture phase distribution. It has other advantages of very good radiation efficiency, more gain and good bandwidth. substrate integrated waveguide fed open slot antenna [WOSA] array can achieve a wide bandwidth with a singlelayer structure, which is attractive for millimeter-wave.

Tapered Slot Array discussed in [5] has both decoupling and radiating structure on the same the surface.For $4 \mathrm{G} / 5 \mathrm{G}$ wireless Devices, dual-polarized crossed slot planar array antenna designed in [2] has a very simple configuration, with good radiation performance, can be fabricated easily. Circularly polarized post-wall waveguide slot array antenna in [1], has the reduction the total number of dielectric layers by a value of two, which there by greatly increases ease of mass production.

\subsection{Slot antenna/antenna array andBandwidth Enhancement}

Bandwidth concerning antenna is defined in terms of radiation parameters. The Bandwidth of an antenna is defined as the range of frequency over which radiation parameters are frequency over which radiations parameters such as half-power beam width (HPBW), levels of side lobes, gain are within specified certain minimum and maximum limits then the range of frequency is defined or considered as the bandwidth. The presence of slots will greatly help in the increase of the bandwidth of the antenna. These structures are periodic that forbids the propagation of all electromagnetic surface waves within a frequency band called band gap thus permitting additional control of the behavior of electromagnetic waves other than the conventional guiding /filtering structure.

Slot antennas are used to achieve improved performances, particularly for broadband and circular-polarization applications with better gain and efficiency. This section conveys the overview of enhancement in bandwidth by the introduction of the Slot antenna/antenna array. 
The type of slot and their applications are mentioned in the table below.

Table1. Application of slot arrays for bandwidth enhancement

\begin{tabular}{|c|c|c|c|c|}
\hline Sl .No. & $\begin{array}{c}\text { Reference } \\
\text { No. }\end{array}$ & Type of slot array & Bandwidth & Application \\
\hline 1 & {$[4]$} & Low-RCS slot array antenna & 7 to $40 \mathrm{GHz}$ & $\begin{array}{c}\text { Radar Cross } \\
\text { Section } \\
\text { Reduction } \\
\end{array}$ \\
\hline 2 & {$[5]$} & Tapered Slot Array & $28 \mathrm{GHz}$ & $\begin{array}{c}\text { 4G/5G Wireless } \\
\text { Devices }\end{array}$ \\
\hline 3 & [6] & $\begin{array}{l}\text { Substrate integrated waveguide fed } \\
\text { open slot antenna }\end{array}$ & $\begin{array}{c}54.0 \text { to } 74.8 \\
\mathrm{GHz}\end{array}$ & $\begin{array}{c}\text { Millimeter-wave } \\
\text { applications }\end{array}$ \\
\hline 4 & {$[7]$} & The tapered slot array & $28 \mathrm{GHz}$ & $\begin{array}{c}\text { Integrated } \\
\text { wireless devices. }\end{array}$ \\
\hline 5 & {$[10]$} & Taper Slot Antenna Array & 0.1 to $67 \mathrm{GHz}$ & Radar Sensors \\
\hline 6 & {$[14]$} & Bow-Tie Slot Antenna Array[ & 29.5 to $37 \mathrm{GHz}$ & $\begin{array}{c}\text { mm-wave } \\
\text { communication }\end{array}$ \\
\hline 7 & [6] & $\begin{array}{l}\text { Substrate-integrated waveguide } \\
\text { (SIW) cavity-backed slot }\end{array}$ & $55.7-66.1 \mathrm{GHz}$ & $\begin{array}{l}\text { Millimeter-wave } \\
\text { wireless systems. }\end{array}$ \\
\hline
\end{tabular}

3

\subsection{Slot antenna/ antenna array in Gain Enhancement}

Gain of an antenna, in general, can be defined as the power radiated by an antenna in the desired direction to that of the power radiated by the reference antenna or an isotropic antenna without any losses. By using a substrate with a higher value of permittivity and using slots of different shapes and sizes the gain of the antenna can be improved.

The below table gives an overview of gain enhancement with the introduction of slots of different shapes along with their applications are also mentioned in the table.

Table2. Application of slot arrays for gain enhancement

\begin{tabular}{|c|c|c|c|c|}
\hline Sl.No. & $\begin{array}{c}\text { Reference } \\
\text { No }\end{array}$ & Type of slot array & Gain & Application \\
\hline 1 & {$[1]$} & $\begin{array}{l}\text { Post-wall waveguide slot } \\
\text { array antenna }\end{array}$ & 15.6-dBi gain & mm-wave communication \\
\hline 2 & {$[2]$} & $\begin{array}{c}\text { Crossed Slot Array } \\
\text { Antenna }\end{array}$ & $24.9 \mathrm{dBi}$ & millimeter-wave applications \\
\hline 3 & {$[6]$} & $\begin{array}{c}\text { Substrate integrated } \\
\text { waveguide fed open slot } \\
\text { antenna }\end{array}$ & $\begin{array}{c}54.0 \text { to } 74.8 \\
\mathrm{GHz}\end{array}$ & millimeter-wave applications \\
\hline 4 & {$[3]$} & $\begin{array}{c}\text { Cavity-backed slot antenna } \\
\text { array }\end{array}$ & $19.7-22.3 \mathrm{~dB}$ & mm-wave communication \\
\hline 5 & [8] & Radial line slot array & $33.8 \mathrm{dBi}$ & mm-wave communication \\
\hline 6 & {$[14]$} & $\begin{array}{c}\text { Bow-Tie Slot Antenna } \\
\text { Array }\end{array}$ & $\begin{array}{c}29.5 \text { to } 37 \\
\mathrm{GHz}\end{array}$ & mm-wave communication \\
\hline 7 & [9] & Slot spiral antenna array & $12.3 \mathrm{dBi}$ & mm-wave applications \\
\hline 8 & {$[15]$} & C-Shaped Slot Antenna & $13.4 \mathrm{dBi}$ & L/S-Band Applications \\
\hline
\end{tabular}


4.

\subsection{Slot antenna/ antenna array Efficiency Improvement}

The efficiency in terms of radiation for an antenna is defined as the ratio of radiation in the required direction or major beam area to the radiation in an unwanted direction or minor beam area. This section gives an overview of the increase in efficiency with the introduction of the Slot antenna/antenna array also the application is mentioned in the table below. By using different shapes of slots, we can improve the efficiency of the antenna as compared to a conventional micro strip patch antenna.

Table3. Application of slot arrays for increase in efficiency

\begin{tabular}{|c|c|c|c|c|}
\hline Sl. No. & $\begin{array}{c}\text { Reference } \\
\text { No }\end{array}$ & Type of slot array & Efficiency & Application \\
\hline 1 & {$[1]$} & $\begin{array}{c}\text { Post-wall waveguide slot } \\
\text { array antenna }\end{array}$ & $57.2 \%$ & $\begin{array}{c}\text { mm-wave } \\
\text { communication }\end{array}$ \\
\hline 2 & {$[2]$} & $\begin{array}{c}\text { Crossed Slot Array } \\
\text { Antenna }\end{array}$ & $76 \%$ & $\begin{array}{l}\text { mm-wave } \\
\text { applications }\end{array}$ \\
\hline 3 & [6] & $\begin{array}{c}\text { Substrate integrated } \\
\text { waveguide fed open slot } \\
\text { antenna }\end{array}$ & $\begin{array}{l}\text { V-band array prototype } \\
\text { is }>68.8 \%, \mathrm{~W} \text {-band } \\
\text { array prototype ranges } \\
\text { from } 41.7 \% \text { to } 75.7 \% \text {. }\end{array}$ & $\begin{array}{l}\text { millimeter-wave } \\
\text { applications }\end{array}$ \\
\hline 4 & [3] & $\begin{array}{c}\text { Cavity-backed slot antenna } \\
\text { array }\end{array}$ & $72 \%$ & $\begin{array}{c}\text { mm-wave } \\
\text { communication } \\
\text { devices. }\end{array}$ \\
\hline 5 & [8] & Radial line slot array & $84.4 \%$. & $\begin{array}{c}\text { mm-wave } \\
\text { communication }\end{array}$ \\
\hline 6 & [14] & $\begin{array}{c}\text { Bow-Tie Slot Antenna } \\
\text { Array }\end{array}$ & $>80 \%$ & $\begin{array}{c}\text { mm-wave } \\
\text { communication }\end{array}$ \\
\hline 7 & [9] & Slot spiral antenna array & $57.3 \%$ & $\begin{array}{l}\text { mm-wave } \\
\text { applications }\end{array}$ \\
\hline 8 & [10] & Tapered Slot Antenna & $83 \%$ & Radar Sensors \\
\hline
\end{tabular}

5

\subsection{Slot antenna/array for getting required polarization}

The type of Polarization depends on the type of slot, the shape of the slot, and the type of feeding mechanism used for feed the slot. To design an antenna with improved bandwidth and efficiency it's better to position the slots on the patch or the ground plane, particularly for broadband and circular-polarization applications.

For eg., A slot antenna in the form of a circular- fed by a strip line hybrid coupler network gives good broadband and polarization will be circular. Square-ring slot radiators when it is fed by pairs of micro strip-line structures used to achieve Dual polarization [13] and C-shaped slot fed by a 50ohms micro strip provides left-hand circular polarization. If we consider the case of Dual-polarized antennas have often brought the exceptional performance to wireless communications systems, at the same time reducing occupied space in wireless base stations and also low cross-polarization and high isolation, enhance signal reception quality at the receiver end. This section conveys an overview of the Bandwidth Enhancement with the introduction of the Slot antenna array. Also type of slot and the application are 
mentioned in the table below.

Table 4. Application of slot arrays for a different type of polarization

\begin{tabular}{|c|c|c|c|c|c|}
\hline Sl.No. & $\begin{array}{c}\text { Reference } \\
\text { No }\end{array}$ & $\begin{array}{l}\text { Type of slot } \\
\text { array }\end{array}$ & TYPE OF FEED & Polarization & Application \\
\hline 1 & [15] & $\begin{array}{l}\text { C-shaped slot and } \\
\text { a 50ohms }\end{array}$ & $\begin{array}{l}\text { Microstrip-fed } \\
\text { port }\end{array}$ & $\begin{array}{l}\text { Left-hand } \\
\text { circular } \\
\text { polarization. }\end{array}$ & $\begin{array}{l}\text { L/S-Band } \\
\text { Applications }\end{array}$ \\
\hline 2 & {$[12]$} & $\begin{array}{l}\text { Cubic Slot } \\
\text { Antenna- }\end{array}$ & $\begin{array}{c}\text { Co-planar } \\
\text { waveguide (CPW) } \\
\text { feed }\end{array}$ & $\begin{array}{l}\text { Omnidirection } \\
\text { al and } \\
\text { broadside } \\
\text { radiation } \\
\text { pattern. } \\
\end{array}$ & $\begin{array}{c}\text { WSN } \\
\text { applications. }\end{array}$ \\
\hline 3 & [9] & $\begin{array}{c}\text { Slot spiral antenna } \\
\text { array- }\end{array}$ & $\begin{array}{c}\text { Printed Gap } \\
\text { Waveguide } \\
\text { (PGW) feeding } \\
\text { network }\end{array}$ & $\begin{array}{l}\text { Right-Hand } \\
\text { Circularly Pola } \\
\text { rized RHCP }\end{array}$ & $\begin{array}{c}\text { Wireless } \\
\text { communication } \\
\text { systems,5G }\end{array}$ \\
\hline 4 & [8] & $\begin{array}{l}\text { Radial line slot } \\
\text { array - }\end{array}$ & $\begin{array}{l}\text { Fed at the center } \\
\text { by a coaxial probe }\end{array}$ & $\begin{array}{l}\text { Circularly } \\
\text { polarized }\end{array}$ & $\begin{array}{c}\text { Wireless } \\
\text { communication } \\
\text { devices }\end{array}$ \\
\hline 5 & [3] & $\begin{array}{c}\text { Cavity-backed } \\
\text { slot antenna array }\end{array}$ & SIW-fed & $\begin{array}{c}\text { Dual } \\
\text { Polarization }\end{array}$ & $\begin{array}{c}60 \mathrm{GHz} \\
\text { communication } \\
\text { systems }\end{array}$ \\
\hline 6 & [2] & $\begin{array}{l}\text { Waveguide slot } \\
\text { array antenna }\end{array}$ & $\begin{array}{c}\text { Fed by a } \\
\text { rectangular } \\
\text { waveguide }\end{array}$ & $\begin{array}{l}\text { circularly } \\
\text { polarized }\end{array}$ & $\begin{array}{c}\text { mm-wave } \\
\text { communication }\end{array}$ \\
\hline 7 & [1] & $\begin{array}{l}\text { Crossed Slot } \\
\text { Array Antenna- }\end{array}$ & $\begin{array}{c}\text { SIW-to GCPW } \\
\text { (grounded co- } \\
\text { planar waveguide) } \\
\text { transitions }\end{array}$ & Dual-Polarized & $\begin{array}{c}\text { mm-wave } \\
\text { communication }\end{array}$ \\
\hline 8 & [13] & $\begin{array}{l}\text { Square-ring slot } \\
\text { antenna array }\end{array}$ & $\begin{array}{l}\text { Microstrip-line } \\
\text { structures }\end{array}$ & $\begin{array}{c}\text { Dual } \\
\text { polarization }\end{array}$ & $\begin{array}{c}\text { 5G Smartphone } \\
\text { Applications }\end{array}$ \\
\hline
\end{tabular}

\section{Conclusion}

Slot antenna and slot antenna array stands promising in meeting the requirement of different application with antenna perspective. Introduction of slot enhances the operating impedance bandwidth, gain and efficiency of an antenna. The dual polarization can be achieved with the slot antenna. Thus it can be concluded that slot antenna and slot antenna array can be designed keeping power, operating frequency and polarization criteria for any required wireless applications.

\section{References}

[1]. Takashi Tomura ,Yuta Saito, And Jiro Hirokawa,"8x2-Element 60-GHz-Band Circularly Polarized Post-Wall Waveguide Slot Array Antenna Loaded With Dipoles",IEEE Antennas Wireless Propag, pp.85950-85957,vol. 8, 2020.

[2] Qingling Yang, Steven Gao, Qi Luo, Lehu Wen , Yong-Ling Ban , Xuexia Yang, Xiaofei Ren, and Jian Wu," Dual-Polarized Crossed Slot Array Antenna Designed on a Single Laminate for Millimeter-Wave Applications", IEEE Trans. Antennas And Propag., pp. 4120-4125, vol.68, NO. 5, MAY 2020.

[3] Zhijiao Chen, Haiwen Liu, Junsheng Yu And Xiaodong Chen," High Gain, Broadband and Dual-Polarized Substrate Integrated Waveguide Cavity-Backed Slot Antenna Array for $60 \mathrm{GHz}$ Band", IEEE Antennas Wireless Propag, pp. 31012-31022,vol. 6, 2018.

[4] Yongtao Jia, Ying Liu, WenboZhang,Jun Wang, And Guisheng Liao,” In-Band Radar Cross Section Reduction of Slot Array Antenna",pp. 23561-23567,vol. 6, 2018.

[5] Muhammad Ikram ,Nghia Nguyen-Trong,And Amin M. Abbosh," Realization of a Tapered Slot Array as Both 
Decoupling and Radiating Structure for 4G/5G Wireless Devices”, IEEE Antennas Wireless Propag,pp. 159112159112,vol. 7, 2019.

[6] Xuan Yi , And Hang Wong," Wideband Substrate Integrated Waveguide Fed Open Slot Antenna Array",pp. 74167-74174,vol. 8, 2020.

[7] Muhammad Ikram ,Nghia Nguyen-Trong,And Amin M. Abbosh,” Common-Aperture Sub-6 GHz and Millimeter-Wave 5G Antenna System”, IEEE Antennas Wireless Propag, pp.199415-199423,vol. 8, 2020.

[8] Mst Nishat Yasmin Koli , Muhamamd U. Afzal, Karu P. Esselle, And Raheel M. HashmI," A Radial Line SlotArray Antenna With Low Side Lobes and a Uniform-Phase, Tapered-Amplitude Aperture Field Distribution", IEEE Antennas Wireless Propag,pp. 208532-208542,vol. 8, 2020.

[9] Elham Baghernia, Mohamed Mamdouh M. Ali And Abdel RazikSebak ," 2 _ 2 Slot Spiral Cavity-Backed Antenna Array Fed by Printed Gap Waveguide", IEEE Antennas Wireless Propag,pp. 170609-170617,vol. 8, 2020.

[10] Haiyang Xia, Tao Zhang ,Lianming Li, And Fu-Chun Zheng," A 1 x 2 Taper Slot Antenna Array With FlipChipInterconnect via Glass-IPD Technology for $60 \mathrm{GHz}$ Radar Sensors", ”,IEEE Antennas Wireless Propag,pp. 61790-61790,vol. 8, 2020.

[11] ChengweiZhao , Xiaoping Li, Chao Sun , He Huang, And Yanming Liu,” Design of a Low-SLL SIW Slot Array Antenna With a Large Declination in Ka-Band ”, ,,IEEE Antennas Wireless Propag,pp. 120541-120547, vol. 7, 2019.

[12] SourenShamsinejad 1, Nabil Khalid, Fatemeh M. Monavar, ShilaShamsadini, Rashid Mirzavand ,Gholamreza Moradi , And PedramMousav ,"Pattern Reconfigurable Cubic Slot Antenna”, IEEE Antennas Wireless Propag,pp. 64401-64410,vol.7, 2019.

[13] Naser OjaroudiParchin, Yasir Ismael Abdulraheem Al-Yasir, Ammar H. Ali, Issa Elfergani, James M. Noras, Jonathan Rodriguez ,And Raed A. Abd-Alhameed," Eight-Element Dual-Polarized MIMO Slot Antenna System for 5G Smartphone Applications", IEEE Antennas Wireless Propag,pp.15612-15622, vol 7, 2019.

[14] Syed M. Sifat Mohamed Mamdouh M. Ali , Shoukry I. Shams , And Abdel-RazikSebak ,"High Gain BowTie Slot Antenna Array Loaded With Grooves Based on Printed Ridge

Gap Waveguide Technology”, IEEE Antennas Wireless Propag,pp.36177-36185, vol.7, 2019.

[15] Rui Xu , Jian-Ying Li, And JieLiu,"A Design of Broadband Circularly Polarized C-Shaped Slot Antenna With Sword-Shaped Radiator and Its Array for L/S-Band Applications", IEEE Antennas Wireless Propag, vol. 6, pp.5892-5896, 2018. 